\title{
Refractory Malignant Glioma
}

National Cancer Institute

\section{Source}

National Cancer Institute. Refractory Malignant Glioma. NCI Thesaurus. Code C142855.

Malignant glioma that does not respond to treatment. 